\title{
CATTLE EGRET AT \\ LA RONGE, SASKATCHEWAN
}

ROD SPOONER, BOX 450, LA RONGE, SASKATCHEWAN. SOJ 1 LO

In mid-October 1985, a medium-sized, white bird was observed being harried near our house by a group of Common Ravens. The bird settled awkwardly in some alders at the lakeshore and I went down, pinned it with a branch, and brought it up to the house. According to The Birds of Canada it was a Cattle Egret. ${ }^{2}$ It was about 15 to 17 in. long, pure white, with a straight yellow bill which was fairIy stout. Its legs were the bluish-grey of an immature bird. The yellow bill separates it from the Snowy Egret and immature Little Blue Heron; the relatively small size differs from the much larger Common Egret.

The bird was very thin, even wasted, and was only a weak, erratic flyer during my brief observation. I put it under my trailered boat in the hopes that the ravens would not discover it until I could return later in the day. However, it had disap- peared within a couple of hours. It is probable that a cat made a meal of it. This bird was obviously beleaguered in our Boreal Forest in late fall, with a skiff of snow on the ground and a raw wind blowing.

The revised Birds of Canada reports the first sighting in Saskatchewan as 1974, with records also of birds in Alberta, British Columbia and the Mackenzie District, Northwest Territories. The closest record to La Ronge is apparently Kinistino.

1 BELCHER,M. 1980. Birds of Regina. Sask. Nat. Hist. Soc. Spec. Publ. 12. Regina, Sask. $151 \mathrm{pp}$.

2 GODFREY,W.E. 1986. The birds of Canada: revised edition. Nat. Mus. of Canada, Ottawa. 595 pp.

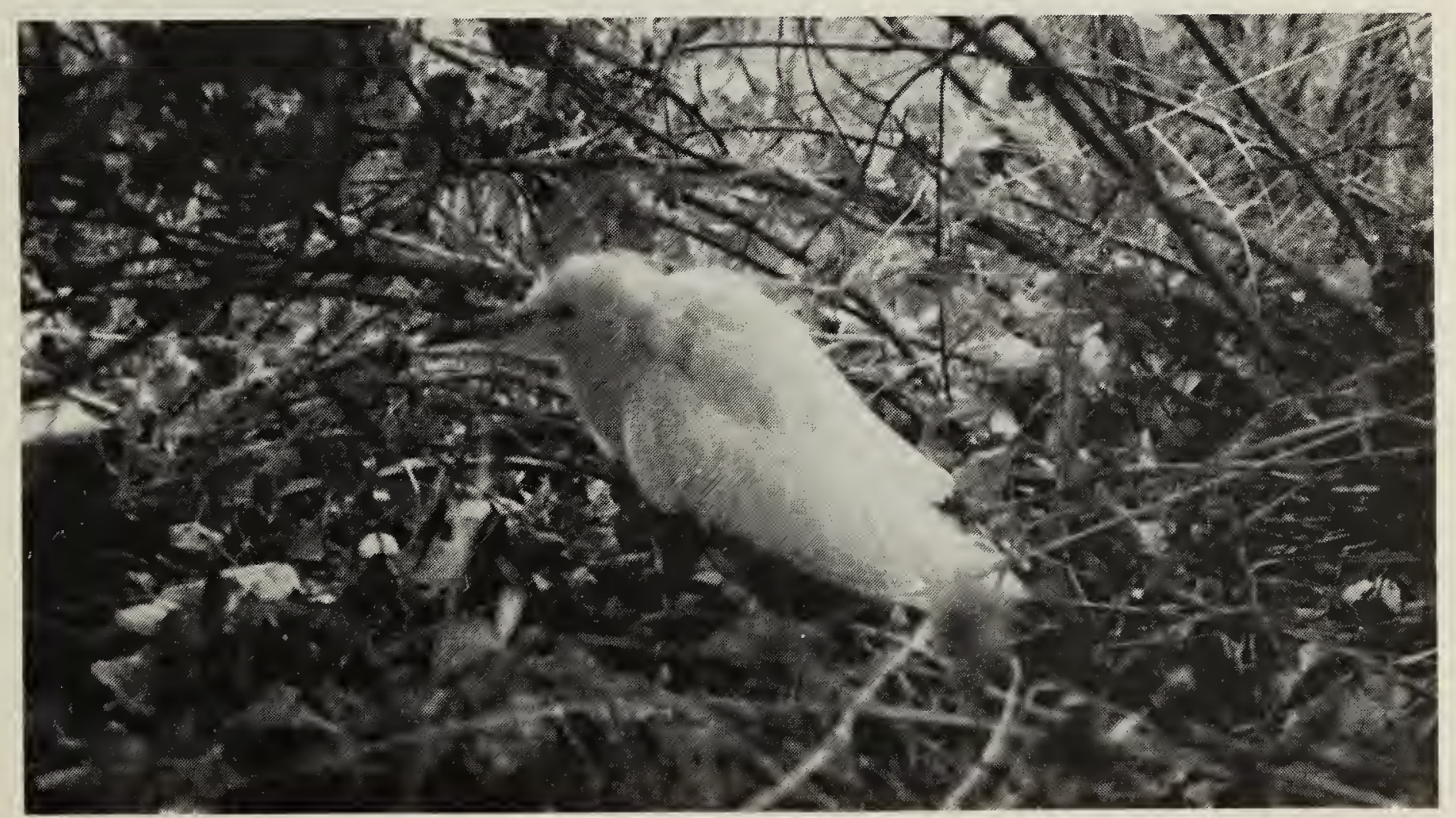

